\title{
Proceedings of the joint meeting of the British Neurosurgery Research Group and the Research Society of Neurological Surgeons (USA), the Copthorne Hotel, Newcastle-upon-Tyne 23-26 May 1996
}

INTRACRANIAL NEOPLASMS OCCURRING IN THE FIRST YEAR OF LIFE: CLINICAL FEATURES, MANAGEMENT, AND OUTCOME

PJ Kane, K Phipps, WFJ Harkness, RD Hayward. The Hospital for Sick Children, Great Ormond Street, London, UK

Intracranial neoplasms are uncommon in the first year of life. The traditional view is that the results of treatment in this age group are poor. The presenting features, clinical management, and functional outcome have been reviewed for 49 children, aged less than one year, who were treated for brain tumours at Great Ormond Street during the period 1982-93.

The cohort ( 26 girls and 23 boys) represents $7 \cdot 5 \%$ of all children with brain tumours referred to the unit in the same period. Increasing head size was the most common presenting symptom and macrocrania (with features of raised intracranial pressure) was the most common sign. Forty six children underwent one or more operations. Twenty two children received radiotherapy and/or chemotherapy. In most cases three or more specialties were involved in clinical management. Twenty nine children survived two years after diagnosis and 19 survived more than five years. Twelve children receive mainstream education.

The management of brain tumours in infants requires a multidisciplinary approach and places significant demands on resources. In view of the infrequency of these tumours it is proposed that the treatment of these children is centralised in designated units to allow efficient use of resources and allow treatment protocols to be developed.

RADICAL SURGERY IN THE TREATMENT OF LOW GRADE GLIOMAS

KS O'Neill, ND Kitchen, PR Wilkins, HT Marsh. Atkinson Morley's Hospital, London, UK

The natural history of low grade gliomas is uncertain. Factors known to correlate with survival include age, gross total removal, and lack of major preoperative and postoperative deficit.

The aim was to develop a standardised surgical technique providing maximal tumour resection with minimal surgical morbidity which will improve long term recurrence rate and survival.

A series of 51 patients with a mean age of 35 admitted with a clinical and radiological diagnosis of low grade glioma since 1989 were studied.

Brain MRI and awake craniotomy with functional mapping was combined with a standardised technique of systematically sampling the resection margins with multiple peroperative smear biopsies. If a microscopic tumour was present, further resection and biopsy was undertaken until clear. To confirm sensitivity of smear cytology and to validate the technique half of each biopsy was sent for smear and half for histological confirmation.

Preoperative baseline was compared with three month, six month, then ongoing yearly assessments incorporating MRI, clinical and epileptic status, psychometry, $\mathrm{AMH}$, and Glasgow outcome scales.

Average follow up was $22 \cdot 2$ months. All but one patient presented with epilepsy and $70 \%$ remain fit free since surgery. There has been no surgical mortality and minimal morbidity with only four new mild permanent neurological deficits. Of the 51 patients, 43 were confirmed low grade tumours on histology. Of those 22 had "total resection" on marginal biopsies and only one has recurred with malignant change. Histological confirmation of smear biopsy has been performed on seven patients so far. In five low grade astrocytomas, both smear and histology correlated, but in two oligodendrogliomas tumour was seen on histology which was not detected on smear.

This technique is logistically simple and safe. Histological results suggest the technique is valid for low grade astrocytomas but not oligodendrogliomas and reasons for this were discussed. Despite this, results are encouraging, and long term follow up will hopefully show a low recurrence rate and increased survival.

CHARACTERISATION OF ENDOTHELIN RECEPTORS IN HUMAN BRAIN TUMOURS

SP Harland, RE Kuc, JD Pickard, AP Davenport. University Department of Neurosurgery, Addenbrooke's Hospital, Cambridge, UK

Endothelin (ET) immunoreactivity, production, and specific receptors have been identified in the human brain. ET is implicated in the pathogenesis of post SAH vasospasm by stimulation of ET receptors or vascular smooth muscle cells. ET increases mitogenesis in glial cells in culture and thus has been implicated as a growth factor in cerebral neoplasia. ET receptor subtypes in normal human cerebral cortex (CC), glioblastoma multiforme (GBM), and meningiomas (MG) were characterised using subtype selective radioligands ([125] $]$-PD151242 $\left(\mathrm{ET}_{\mathrm{A}}\right)$ and $\left.\left[{ }^{125} \mathrm{I}\right]-\mathrm{BQ} 3020\left(\mathrm{ET}_{\mathrm{B}}\right)\right)$. In saturation binding assays PD15124 bound with high affinity to a single population of ET receptors in CC $\left(n=5 ; K_{D}=1.07(0.14)\right.$ $\mathrm{nM} ; \mathrm{B}_{\max }=25.06(3.4) \mathrm{fmol} / \mathrm{mg}$ protein); $\mathrm{GBM}\left(\mathrm{n}=5 ; \mathrm{K}_{\mathrm{D}}=1.62(0.20) \mathrm{nM} ; \mathrm{B}_{\max }=\right.$
$147 \cdot 04(62 \cdot 8) \mathrm{fmol} / \mathrm{mg}$ protein) and MGs (n $=5 ; \quad K_{\mathrm{D}}=2.65(0.33) \quad \mathrm{nM} ; \quad \mathrm{B}_{\mathrm{max}}=364.8$ $(74 \cdot 2) \quad \mathrm{fmol} / \mathrm{mg}$ protein). BQ3020 also bound with high affinity to a single population of ET receptors in CC $\left(n=5 ; K_{D}=\right.$ $0.84(0.2) \mathrm{nM} ; \mathrm{B}_{\max }=232.7(38.2) \mathrm{fmol} / \mathrm{mg}$ protein); GBM (n $=5 ; \quad K_{D}=1.38(0.28)$ $\mathrm{nM} ; \mathrm{B}_{\max }=234.0(153.6) \mathrm{fmol} / \mathrm{mg}$ protein) and MGs $\left(n=5 ; K_{D}=0.21(0.06) n M ; B_{\max }\right.$ $=64.0(25 \cdot 8) \mathrm{fmol} / \mathrm{mg}$ protein $)$. Autoradiography revealed a high concentration of $\mathrm{ET}_{\mathrm{A}}$ receptors within the pial and intraparenchymal vessels and meninges overlying CC. Grey and white matter were diffusely $\mathrm{ET}_{\mathrm{B}}$ positive. GBM had a strongly vascular pattern of $\mathrm{ET}_{\mathrm{A}}$ distribution. $\mathrm{ET}_{\mathrm{A}}$ receptors were dense and homogeneous in MGs. In competition experiments the orally active non-peptide antagonist PD156707 had high affinity and selectivity for the $\mathrm{ET}_{\mathrm{A}}$ receptor. Selective $\mathrm{ET}_{\mathrm{A}}$ receptor manipulation may have potential benefits in vascular disease and neoplasia without producing detrimental effects on $\mathrm{ET}_{\mathrm{B}}$ positive brain parenchyma.

AN INVESTIGATION INTO THE EXPRESSION OF CD44 INVASION RELATED ANTIGEN IN GLIAL TUMOURS AND ITS POSSIBLE ROLE IN GUIDING RESECTION

KS O'Neill, KK Martin, AP King, PR Wilkins, HT Marsh, GJ Pilkington, BA Bell. Atkinson Morley's Hospital and Institute of Psychiatry, London, UK

CD44 is a major receptor for hyaluronic acid enabling cell binding and motility within the extracellular matrix. Evidence shows an upregulation on certain neoplastic cells and suggests a key role in tumour invasion. The differential expression of CD44 in resection smears of glial tumours was investigated in relation to the proliferating tumour mass, the invading tumour margin, and adjacent brain. Characterisation of invasion marker expression in both low and high grades may help to utilise this information to determine the patterns, extent, and limits of invasion. This is of particular importance to the treatment of low grade gliomas, for which there is increasing clinical evidence that radical excision reduces recurrence rate and may have considerable survival benefit.

At craniotomy samples are taken from the tumour mass, macroscopic margin, and outer band of surrounding brain. These areas are confirmed with peroperative diagnostic smear cytology. Each sample undergoes smear and cell culture for later immunocytological analysis of tumour and invasion related antigens.

So far 12 patients have been analysed for high grade astrocytomas and eight low grade gliomas, three of which were oligoden- 
drogliomas. The pattern of expression was similar for all tumour types. Little or no expression of CD44 was seen within the tumour bulk but an increase in expression was seen in the margins and also outer band despite this area being confirmed in some low grades as tumour free. This pattern of CD44 expression suggests an absence in proliferating cells in the tumour mass and an upregulation at the margins supporting its role in invasion. However its presence in the outer band may simply reflect that the true outer limits of the tumour had not been reached or represent an upregulation of the receptor on both neoplastic cells and reactive glia. The significance of this remains to be established and studies on future patients and specific molecular splice variants of CD44 are planned.

NITRIC OXIDE SYNTHASE ACTIVITY IN HUMAN GLIOBLASTOMA: A HISTOCHEMICAL STUDY

GR Swaroop, JW Ironside, IR Whittle. Department of Clinical Neurosciences, Western General Hospital, Edinburgh, UK

In the CNS regulation of vascular tone and blood flow, neuronal signalling, and immune mechanisms are mediated by NO. Nitric oxide synthase (NOS), the enzyme for synthesis of NO, exists as inducible (iNOS) and constitutive (cNOS) forms. As glioblastoma are composed of dedifferentiated astrocytes, neoplastic endothelial cells, and infiltrating macrophages this study was undertaken to determine whether they express NOS.

Frozen tissue from 19 human glioblastoma were studied. NADPH diaphorase histochemistry was performed on $20 \mu$ sections. Adjacent $5 \mu$ sections were stained with haematoxylin and eosin. Formation of a purplish formazan deposit was taken as positive. Under light microscopy intensity, locality, relation to specific tumour cells, and vessels were assessed and compared with normal brain.

All the tumours showed parenchymal positivity. The pattern varied between tumours and different tumour regions. Necrotic areas showed no NOS activity. Vascular endothelium showed the most consistent pattern. In all the endothelium was stained denser compared to tumour parenchyma and normal vasculature. Endothelial proliferation in particular showed positivity. This study has demonstrated that human glioblastoma express NOS. The staining is more pronounced in the neoplastic cells and blood vessels of glioblastoma than normal brain. This suggests that NO may regulate the normal resting tone of arterioles, hence tumour blood flow.

MODIFIED VIRAL THERAPY FOR MALIGNANT GLIOMAS: IN VITRO ASSESSMENT OF ICP 34.5 MUTANT INDICATES A POTENTIALLY EFFECTIVE CLINICAL THERAPY

GS Cruikshanks, EA McKie, AR MacLean, AD Lewis, R Rampling, SM Brown. Departments of Neurosurgery and NeuroVirology, Institute of Neurological Sciences, Southern General Hospital, Glasgow, UK

Conventional therapy for high grade glial brain tumours involves maximal resection and radiation. Even with the addition of adjuvant chemotherapy the median survival still approximates to one year. There is a clear need for alternative therapies which address both the focal and diffuse nature of these heterogeneous tumours. One approach is to use viruses as tumoricidal agents in their own right.

The potential therapeutic use of the herpes simplex virus (HSV) mutant 1716 has been evaluated. The mutant is deleted in the RL1 gene and fails to produce the virulence factor ICP $34 \cdot 5$.

1716 replication was analysed in both established human glioma cell lines, and in primary cell cultures derived from human tumour biopsy material. In most cultures, virus replication occurred and consequential cell death resulted. In most cell lines which were non-permissive for mutant replication, premature shut off of cell protein synthesis was induced in response to lack of expression of ICP 34.5

Hence RLl negative mutants have the advantage of providing a double hit phenomenon whereby cell death could occur by either pathway. Moreover, 1716 by virtue of its selectivity to replicate within a tumour cell has the potential to immediately deliver a "suicide" gene product to the required site, and facilitate a new and possibly effective tumour therapy.

PHENYLBUTYRATE AS A NOVEL THERAPEUTIC COMPOUND FOR THE TREATMENT OF MALIGNANT GLIOMA: FROM LABORATORY BENCH TO PATIENT BEDSIDE

HH Engelhard, HA Duncan, RJ Homer Neurosurgery, Northwestern University, Suite 500, 233 E Erie, Chicago Il, USA

Sodium phenylbutyrate (SPB) is a phenylfatty acid which induces a differentiation response in many malignant cell lines. In these studies, the effect of SPB was investigated in cultured rat and human glioma cells, primary human glioblastoma (GBM) explants and in an animal tumour model. Clinical trials of SPB for the treatment of patients with GBM have now been started. Cells were analysed to assess the effect of SPB on proliferation, cell cycle distribution, morphology, migration, invasiveness, apotosis, and $c-m y c$ and urokinase expression Techniques included light and immunofluorescence microscopy, flow cytometry, scratch and Matrigel assays, DNA electrophoresis, and northern blot analysis

Results showed that SPB treatment decreased cell counts and $\% \mathrm{~S}$ phase cells in a dose dependent fashion. For U118MG cells, counts were $100(21) \%, 54(7) \%, 43$ (13) $\%$, and $27(7) \%$ for 72 hours of treatment with $0,2,4$, and $8 \mathrm{mM}$ SPB, respectively. Primary GBM explant cells had counts of $100(5) \%, 71(7) \%, 51$ (3)\%, and $42(4) \%$. For C6 cells, $\% S$ phase was 32 (3) $\%, 27(1) \%, 18(2) \%$, and $14(3) \%$, respectively. Treatment with SPB caused the extrusion of long cytoplasmic processes, similar to those of differentiated astrocytes, and inhibition of cellular migration, but did not cause apotosis. SPB caused down modulation c-myc and urokinase expression by $20-75 \%$ depending on cell type and duration of treatment. Rats tolerated SPB infusion without discernable toxicity at clinically relevant doses. SPB is available in an oral formulation for patient use. For all these reasons, SPB continues to be an extremely promising novel agent for use in patients with malignant glioma.
DIFFERENTIAL EFFECTS OF COMBINATIONS OF CAMPTOTHECIN DERIVATIVES AND ETOPOSIDE ON GLIOBLASTOMA AND COLON CARCINOMA

RA Fenstermaker, GJ Castglia, MJ Ciesielski. Department of Neurosurgery, SUNY at Buffalo School of Medicine and Biomedical Sciences, and Roswell Park Cancer Institute, Buffalo, New York, USA

The limited success of standard chemotherapy for malignant gliomas suggests the need to identify combinations of agents with synergistic activity against gliomas. Topoisomerases (topo) are nuclear enzymes that relieve the torsional constraint of DNA imposed during replication and transcription. Because these two nuclear factors exhibit related actions, the possibility of synergistic cytotoxicity between the two classe of topoisomerase inhibitors was evaluated. Combinations of topo I inhibitors 9 aminocamptothecin (9-AC) or topotecan (TPT) and a topo II inhibitor etoposide (VP-16) were tested for synergistic cytotoxicity in glioblastoma cell lines (U87, U118, U138, U373, SW1088, SW1783) and a colon carcinoma cell line (HT-29) using suforhodamine $\mathrm{B}$ (SRB) assays. $\mathrm{IC}_{50} \mathrm{~s}$ for 9AC ranged from $7 \mathrm{nM}-1 \cdot 11 \mu \mathrm{M}$, and TPT $\mathrm{IC}_{50} \mathrm{~s}$ ranged from $32 \mathrm{nM}-0 \cdot 568 \mu \mathrm{M}$. Cells exposed to VP-16 had $\mathrm{IC}_{50} \mathrm{~s}$ from $1 \cdot 48-13.6 \mu \mathrm{M}$. When the two types of topo inhibitors were combined, the $\mathrm{IC}_{50} \mathrm{~s}$ were reduced up to fivefold. The combination index (CI) for drug interaction was significantly less than $1.0 \quad(P<0.05)$ for all glioblastoma cells indicating synergy. In colon carcinoma, the CIs of the combined agents were both equal to 1.0 indicating additivity. A differential effect on DNA fragmentation was also apparent with mild antagonism in colon carcinoma and synergy in glioblastoma. In glioblastoma but not colon carcinoma, subcytotoxic doses of 9AC led to enhanced cytotoxicity of VP-16 and vice versa. These findings suggest a tissue specific pattern to topo I and topo II inhibitor interaction producing synergistic cytotoxicity in glioblastoma cells.

INFLUENCE OF DOMINANT HEMISPHERIC LOCALISATION ON TUMOUR ASSOCIATED LANGUAGE DYSFUNCTION

AM Thompson, $\mathbf{R}$ Taylor, $\mathbf{R}$ Sellar, IR Whittle. Department of Clinical Neurosciences, Western General Hospital, Crewe Road, Edinburgh, UK

Current knowledge regarding patterns of language localisation in the dominant hemisphere has been derived from stroke studies. Classically a lesion in the territory of the third frontal gyrus will result in a non-fluent or Broca's dysphasia whereas Wernicke's dysphasia will follow damage to the superior temporal gyrus. In this study the relation between the location of solitary tumours in the dominant hemisphere and patterns of language disorders was studied to evaluate the hypothesis that tumour induced impairments of language do not conform with the patterns of localisation in stroke. Patients with a solitary dominant hemispheric tumour were assessed using the Western aphasia battery and Boston naming test before biopsy or resection. All patients were on steroids (mean $9.3 \mathrm{mg} /$ day). Tumours were identified on either axial CT or MRI Tumour location was assigned to one or 
more of six regions of the dominant hemisphere by placing a specially designed brain template over each scan. Statistical analysis to determine relations between language scores and tumour location was carried out using the Pearson $r$ with Bonferroni correction.

Sixty patients were studied. There were highly significant correlations $(P<0.001)$ between the presence of tumour in Broca's area and (a) expressive language deficits; $(b)$ anomia; and $(c)$ impaired comprehension of language. Several specific language abnormalities were also found in patients with tumours in the temporal pole. There was no significant association between any feature of language dysfunction and tumours in the region of Wernicke's area.

These results confirm the original hypothesis: Broca's dysphasia is not typically associated with impaired comprehension; anomia is not restricted to lesions in Broca's area; and damage to Wernicke's area usually results in specific patterns of language dysfunction whereas lesions in the temporal pole do not. The reason for these findings and the use of templates was discussed.

SHOULD ENDOLYMPHATIC SAC TUMOURS BE CONSIDERED PART OF THE VON-HIPPELLINDAU COMPLEX?

RE Tibbs Jr, AP Bowles Jr. Neurosurgery, University of Mississippi Medical Centre, 2500 North State St, Jackson, Mississippi, USA

A patient with an endolymphatic sac tumour and van Hippel-Lindau disease is reported. An exhaustive literature review yielded only seven other reported cases. A summary of their characteristics was given. Endolymphatic sac tumours are rare and have been recently identified as a source of neoplasia. Von Hippel-Lindau (vHL) disease is characterised by numerous cystic and solid neoplasms. The vHL tumour suppressor gene has been identified, and, with it, others have been able to show similar genetic mutation in some of the tumours associated with $\mathrm{vHL}$ disease. A similar mutation in the endolymphatic sac tumour occurred in this patient and it is proposed that this tumour should be included in the range of neoplasms associated with vHL disease.

\section{HEAD INJURY PREDICTION REVISITED}

IR Chambers, L Treadwell, A McNay, AD Mendelow. Regional Medical Physics Department and Department of Surgery (Neurosurgery), University of Newcastle Upon Tyne, UK

In 1989 the Northern Regional Health Authority created a multidisciplinary head injury audit team. Its aim was to investigate the practice of head injury management and to make recommendations as to how it could be improved. To predict the likelihood of an adverse outcome a database of 1143 admissions to Newcastle General Hospital (NGH) during 1987, 1988, and 1990 was analysed and a very simple model for outcome prediction based upon four main prognostic indicators (verbal orientation, pupillary reaction, motor response, and age) was developed (table).

Between January 1992 and June 1995 there was a further total of 2591 admissions

Model for prediction of outcome after head injury (favourable $=G R / M D$ )

\begin{tabular}{|c|c|c|c|}
\hline \multirow[b]{2}{*}{ Group } & & \multicolumn{2}{|c|}{$\%$ Favourable outcome on discharge } \\
\hline & & $1987 ; 88 ; 90$ & $1992-5$ \\
\hline 1 & Verbally oriented & $99 \cdot 4$ & $98 \cdot 1$ \\
\hline 2 & $\begin{array}{l}\text { Not verbally oriented } \\
\text { Age under } 40 \\
\text { Good motor response } \\
\text { Equal and reacting pupils }\end{array}$ & $96 \cdot 3$ & $81 \cdot 1$ \\
\hline 3 & $\begin{array}{l}\text { Not verbally oriented } \\
\text { Age } 40 \text { or over } \\
\text { Good motor response } \\
\text { Pupils equal and reacting }\end{array}$ & $89 \cdot 4$ & $60 \cdot 2$ \\
\hline 4 & $\begin{array}{l}\text { Not verbally oriented } \\
\text { Good motor response } \\
\text { Pupils not equal and reacting }\end{array}$ & $72 \cdot 7$ & $70 \cdot 4$ \\
\hline 5 & $\begin{array}{l}\text { Not verbally oriented } \\
\text { Not a good motor response } \\
\text { Pupils equal and reacting }\end{array}$ & $55 \cdot 1$ & $63 \cdot 3$ \\
\hline 6 & $\begin{array}{l}\text { Not verbally oriented } \\
\text { Not a good motor response } \\
\text { Pupils not equal and reacting }\end{array}$ & $27 \cdot 9$ & $28 \cdot 8$ \\
\hline
\end{tabular}

$\mathrm{GR}=$ Good recovery; $\mathrm{MD}=$ moderate disability .

to NGH. Of these 2569 had the relevant data to recalculate the outcome prediction model.

The prediction model calculated on the original data was confirmed by the analysis of the later data. Whereas the model is simple it provides a useful tool to identify those cases which may benefit from further audit.

ANATOMY OF DELAY IN PATIENTS UNDERGOING CRANIOTOMY FOR ACUTE TRAUMATIC INTRACRANIAL HAEMATOMA

K Seex, F McNeil, G Teasdale. Department of Neurosurgery, Southern General Hospital, Glasgow, UK

Delay in evacuation of traumatic intracranial haematoma (TIH) can adversely affect outcome. To identify where delays occur and to investigate whether the site of CT-local hospital or neurosurgical unit (NSU)affects the time to surgery, data on 50 consecutive patients arriving at the neurosurgical intensive care unit between March 94 and February 95 was prospectively collected. Clinical information, time to accident and emergency, NSU, CT, theatre, incision and any delays, elective or otherwise, were recorded.

There were 44 male and six female patients with a mean age of 40 years (range 1-67). $45 / 50(90 \%)$ patients arrived at the NSU in coma or sedated and ventilated. $21 / 50(42 \%)$ had local hospital CT. $29 / 50$ $(58 \%)$ had scans at the NSU. The corresponding median times from arrival at the local hospital to arrival at the NSU were 260 and 183 minutes and the median times from arrival at the NSU until incision were 100 and 110 minutes respectively.

In "static" patients, waiting for local hospital CT introduces substantial delay. Within the NSU there is minimal delay in obtaining CT but opportunities exist to accelerate theatre arrangements.

EFFECTS OF A SIMPLE PATIENT SPECIFIC REMINDER ON IMPLEMENTATION OF GUIDELINES ON HEAD INJURY IN ACCIDENT AND EMERGENCY DEPARTMENTS

$S$ Bergin, $\mathrm{AD}$ Mendelow, $\mathbf{R}$ Thomson Directorate of Professional Advice and Public Health, Tees Health/Department of Epidemiology and Public Health, Newcastle University, UK
Head injury is a cause of preventable morbidity and mortality. Guidelines on selection for skull radiography (SXR) and admission have been developed. A controlled study in three accident and emergency departments evaluated the impact of patient specific reminders (guidelines attached to the medical record). Appropriateness of SXR and admission was assessed from the medical record $(n=2539)$. Significant changes over time in the recording of signs and symptoms occurred in control and intervention departments. However, there was no change in the apparent appropriateness of SXR or admission decisions over time or following intervention. There was no significant difference in the proportion of cases managed appropriately, at each site, before and after implementation of the guidelines (for SXR: before 69.0-70.5\%, after $66 \cdot 6-70.9 \%$; for admission: before $91 \cdot 7-94 \cdot 8 \%$, after $93 \cdot 0-95 \cdot 0 \%$ ). This patient specific reminder had no apparent effect on the implementation of these guidelines in accident and emergency departments. None the less, since the introduction of the guidelines, regional referral of intracranial haematomas has more than doubled.

SAFETY OF EXTENDED ADMINISTRATION TO HEAD INJURED PATIENTS OF APTIGANEL HCL (CERESTAT ${ }^{\mathbb{E}}$ ), A NON-COMPETITIVE NMDA ANTAGONIST

G Teasdale, A Wagstaff, on behalf of the 1102-005 (CERESTAT ${ }^{\S}$ ) Studies Group. Institute of Neurological Sciences, Glasgow, UK

Aptiganel $\mathrm{HCl}$ (CERESTAT ${ }^{\S}$, Cambridge NeuroScience) shows powerful neuroprotection experimentally and is unique as the only non-competitive NMDA antagonist being developed for clinical use in traumatic brain injury. The safety of neuroprotective dosages given over clinically relevant durations has been investigated. Severely head injured patients (GCS < 8) were studied in seven centres in Scotland and the United States within 12 hours of injury. Initially patients were randomly allocated either to placebo (n $=9)$ or Aptiganel $(n=24)$ given over periods increasing from 12 to 72 hours; 14 further patients received Aptiganel in a 72 hour open study. Pharmacokinetic studies showed that plasma concentrations of Aptiganel of 30 $\mathrm{ng} / \mathrm{ml}$ were achieved and maintained (three times the neuroprotective level experimentally). One patient received an inadvertent 
overdose and developed seizures; otherwise there were no unexpected treatment related adverse effects. Mean blood pressure, intracranial pressure, and cerebral perfusion pressure did not differ between patients randomised to placebo or Aptiganel but ICP variability was less in the latter group. Amongst randomised patients one out of nine receiving placebo and four out of 24 receiving Aptiganel died. Overall mortality at two months was $35 \%$, death in each case being attributed to severity of injury. We conclude that Aptiganel $\mathrm{HCl}$ can be given safely, at a clinically relevant dosage $(15 \mathrm{mg}$ bolus plus 3 mg per hour) for 72 hours and that the efficacy of this regimen should be studied in a definitive phase III trial.

IS HYPNOTRAEMIA IN ACUTE HEAD INJURY A SIGNIFICANT SECONDARY INSULT?

W Poon, Y Lolin, K Goh, V Yeung, XL Zhu, J Hsaing, C Cockram. Neurosurgical Unit, Prince of Wales Hospital, The Chinese University of Hong Kong

The aim of this study was to determine the incidence and pathophysiology of hyponatraemia (plasma sodium, $\mathrm{pNa}<134 \mathrm{mmol} / \mathrm{l}$ ) after acute head injury, and to correlate this with the outcome. Head injured patients requiring intensive care management were studied prospectively, with daily sampling of plasma/urine for biochemistry and their derived parameters, central venous pressure (CVP) recording, plasma atrial natriuretic peptide (ANP), and antidiuretic hormone (ADH) measurements.

Thirty consecutive patients were studied. Eleven patients $(37 \%)$ had at least one episode of severe hyponatraemia ( $\mathrm{pNa}<125$ $\mathrm{mmol} / \mathrm{l}$ ) during the first week of admission, and eight $(27 \%)$ had mild hyponatraemia (pNa 125-134 mmol/l). Of these 19 patients with hyponatraemia, $11(58 \%)$ had cerebral salt wasting (CSW) associated with a raised plasma ANP $(92.8(26.8) \quad v \quad 48.3(31.2)$ $\mathrm{pg} / \mathrm{ml}, \mathrm{P}<0.05)$ but not $\mathrm{ADH}$ concentrations $(8.9(4 \cdot 1)$ v $6.5(3.2) \mathrm{pg} / \mathrm{ml})$, whereas eight patients had the syndrome of inappropriate secretion of $\mathrm{ADH}$ (SIADH). Severe hyponatraemia was associated with a higher incidence of unfavourable outcome $(8 / 11$ $(72 \%) v$ mild hyponatraemia $1 / 8(13 \%) v$ normal $3 / 11(27 \%) ; \mathrm{df}=2, \chi^{2}=8 \cdot 2, \mathrm{P}=$ 0.02).

Severe hyponatraemia $\quad(\mathrm{pNa}<125$ $\mathrm{mmol} / \mathrm{l}$ ) in acute neurotrauma was a definite secondary insult resulting in poorer outcome. Accurate diagnosis and immediate treatment were therefore essential to prevent further brain damage.

PLASMA SUBSTITUTE DIASPIRIN CROSS LINKED HAEMOGLOBIN (DCLHB) REDUCES RAISED INTRACRANIAL PRESSURE IN A RODENT MODEL OF IMPACT ACCELERATION HEAD INJURY

I Piper, $M$ Souter, $\mathbf{P}$ Andrews, $M$ Garrioch. Department of Clinical Neurosciences, Western General Hospital, UK

Diaspirin cross linked haemoglobin (DCLHb) is a new oxygen carrying plasma substitute with vasoconstrictive properties mediated by high affinity binding of nitric oxide by the haem moiety. The aim of this study was to assess, using a rodent model of head injury, the effects of DCLHb on cere- bral blood flow (CBF) and raised intracranial pressure (ICP).

Ten anaesthetised, paralysed, and ventilated Sprague-Dawley rats were randomly allocated to either treatment (DCLHb 400 $\mathrm{mg} / \mathrm{Kg} \mathrm{IV}$ ) or placebo (plasma protein substitute $4.5 \% \mathrm{IV}$ ) groups. After a $450 \mathrm{~g} \times 2$ $m$ weight drop injury, all animals underwent a 30 minute period of bilateral carotid ligation in combination with a phlebotomy induced period of hypotension (blood pressure (BP) $40-50 \mathrm{~mm} \mathrm{Hg}$ ). After reperfusion, $\mathrm{DCLHb}$ or the placebo agents were infused and the animals then instrumented for measurement of intraventricular ICP and CBF in the region of sensorimotor cortex using the hydrogen clearance technique. BP, ICP, CPP (BP-ICP), and CBF were measured at four hours after injury in all animals after which animals were given a terminal anaesthetic.

Analyses showed that DCLHb significantly reduced ICP $(13(6) \rightarrow 3(3) \mathrm{mm}$ $\mathrm{Hg}, \mathrm{P}=0.01)$, increased CPP (64 (25) $\rightarrow$ $102(19) \mathrm{mm} \mathrm{Hg}, \mathrm{p}=0.024)$ and increased CBF $(22(6) \rightarrow 30(7) \mathrm{ml} / 100 \mathrm{~g} / \mathrm{min}, \mathrm{p}=$ 0.022 ). Neuropathological studies are in progress to determine if these beneficial effects of DCLHb on the pathophysiology after head injury translate into neuroprotection.

\section{GLUTAMATE EXCITOTOXICITY IS}

POTENTIATED BY NON-LETHAL HYPOXIA IN ORGANOTYPIC HIPPOCAMPAL SLICE CULTURES

AK Pringle, C Gascoigne, LE Sundstrom, F Iannotti. Clinical Neurological Sciences, University of Southampton, Southampton General Hospital, Southampton, UK

Antagonists of glutamate receptors significantly reduce ischaemic neuronal damage. However, the concentration of extracellular glutamate in the ischaemic brain is not sufficient to induce neuronal damage in acute slices of neuronal tissue. Glutamate toxicity in ischaemia must therefore result from combination of factors. The neurotoxicity of simultaneous exposure of cultured hippocampal slices to low levels of glutamate and hypoxia has been investigated. The effects of glutamate excitotoxicity were investigated by exposing the cultures to 0.01-10 mM glutamate for 60 minutes. Other cultures were additionally exposed to hypoxia, induced by placing cultures in an atmosphere saturated with $95 \% \mathrm{O}_{2} / 5 \% \mathrm{CO}_{2}$. After 60 minutes cultures were returned to normal medium for 24 hours, after which cell death was quantified using propidium iodide (PI). Exposure to glutamate (0.3-10 $\mathrm{mM}$ ) or hypoxia alone did not produce PI fluorescence in the neuronal cell layers. However, 60 minutes exposure to combined hypoxia and glutamate produced a significant increase in PI staining. PI fluorescence was observed in $46.3(8.9) \%$ of CAl and $41.7(9 \cdot 9) \%$ of CA3 after simultaneous exposure to $0.3 \mathrm{mM}$ glutamate and hypoxia. These data show that hippocampal neurons in organotypic culture are remarkably resistant to glutamate toxicity up to $10 \mathrm{mM}$ under normal conditions. However, in conditions in which neuronal energy is compromised, very low concentrations of glutamate become toxic. Thus after cerebral ischaemia, a small increase in extracellular glutamate may be sufficient to produce appreciable neuronal damage.
MITOCHONDRIAL FUNCTION IN THE AGING ISCHAEMIC RAT BRAIN

M Davis, T Whiteley, DM Turnbull, AD Mendelow. Departments of Surgery (Neurosurgery), Neurology, and Medicine (Geriatrics), University of Newcastle upon Tyne, UK

Age related impairments of cerebral function may be in part secondary to structural and functional decline in brain mitochondria. Such oxidative damage to mitochondrial deoxyribonucleic acid (DNA) and the subsequent defects in oxidative phosphorylation might also be implicated in the pathogenesis of ischaemic neuronal damage and may thereby contribute to the age related increase in infarct volume that has been documented in a rodent model of focal cerebral ischaemia. This hypothesis was evaluated by assessing mitochondrial function in both ischaemic and non-ischaemic brain tissue of adult and aged male Wistar rats, six hours after occlusion of the left middle cerebral artery by thermocoagulation, according to the technique of Tamura. Mitochondria were harvested from the left and right cerebral hemispheres of both age groups and the activities of enzymes involved in catalysing oxidative phosphorylation, including the activities of citrate synthase and the enzyme complexes I, II, III, and IV were assessed in each hemisphere. Data was analysed using Student's $t$ test and the results are presented as means with their standard errors.

Complex I activity was lower in ischaemic brain, with mean values of $91.1(8.8)$ $\mathrm{nmol} / \mathrm{min} / \mathrm{mg}$ protein and $126.7(14)$ $\mathrm{nmol} / \mathrm{min} / \mathrm{mg}$ protein in the left and right hemispheres respectively $(P<0.05, n=13)$ and also declined with aging. The mean activity in aged rats $(n=7)$ was $97 \cdot 4(15)$ $\mathrm{nmol} / \mathrm{min} / \mathrm{mg}$ protein compared with 160.9 (18) $\mathrm{nmol} / \mathrm{min} / \mathrm{mg}$ protein in adults $(\mathrm{n}=6$, $P<0.05)$. The activities of complexes II and IV were not significantly impaired in ischaemic brain, but both declined with aging. The mean activity of complex II in aged rat brain was $222 \cdot 1$ (34) $\mathrm{nmol} / \mathrm{min} / \mathrm{mg}$ protein, compared with $371 \cdot 1$ (39) $\mathrm{nmol} / \mathrm{min} / \mathrm{mg}$ protein in adults $(P<0.05)$, whereas mean values for complex IV were $3.32(0.52) \mathrm{K} / \mathrm{s} / \mathrm{mg}$ protein and $5.41(0.46)$ $\mathrm{K} / \mathrm{s} / \mathrm{mg}$ protein respectively $(\mathrm{P}<0.05)$. Complex III and citrate synthase activities were not affected by aging or ischaemia.

Aging was associated with significant impairments of cerebral mitochondrial function, with decline in the activities of complexes I, II, and IV. The individual respiratory chain complexes also exhibited selective vulnerability to a focal cerebral ischaemic lesion, with significant impairment of complex I activity in the lesioned hemisphere of both age groups. The age related decline in complex I activity may be important in the enhanced susceptibility of the aging brain to ischaemic neuronal damage.

BLOOD FLOW VELOCITY IN BASILAR ARTERY AND CEREBRAL CORTICAL

MICROCIRCULATION AFTER SYSTEMIC ADMINISTRATION OF L-NAME IN RABBITS

HK Richards, Ewa Kozniewska, M Czosnyka, JD Pickard. MRC Cambridge Centre for Brain Repair and Academic Neurosurgery Unit, Addenbrookes Hospital, Cambridge, UK and Department of Clinical 
and Applied Physiology, School of Medicine, Warsaw, Poland

Transcranial Doppler indices of blood flow velocity (FV) pulsatility are becoming widely used in clinical practice. To investigate the effect of nitric oxide (NO) on FV pulsatility, the effect of inhibition of basal release of NO on FV in the basilar artery and cerebrocortical microcirculation was assessed using an experimental model.

In 12 New Zealand White rabbits, FV, cortical laser Doppler flux (LDF), and arterial blood pressure (AP) were recorded for 60 minutes after inhibition of basal release of $\mathrm{NO}$ by systemic administration of $\mathrm{N}^{\mathrm{G}}$ nitroL-arginine methyl ester, L-NAME $(6 \mathrm{mg} / \mathrm{kg}$ intravenously).

After administration of L-NAME, AP increased and FV fell rapidly, both becoming significantly $(P<0.01)$ changed from baseline values by the third minute and remained significantly raised or decreased for the remainder of the experiment. LDF exhibited a significant but slow decrease with time. It reached a value which was significantly lower than baseline $(P<0.01)$ at 40 minutes after L-NAME administration.

L-NAME induced NOS inhibition in rabbits provokes a rapid reaction in FV in the basilar artery and a slow reduction in cortical microcirculation. A gradual increase in cerebrovascular resistance was therefore preceded by a rapid decrease in the compliance of the large cerebral arteries.

DIABETES MELLITUS ALTERS THE PATHOPHYSIOLOGY OF HAEMORRHAGIC STROKE: THE ROLE OF NITRIC OXIDE PATHWAYS

IP Fouyas, PAT Kelly, IM Ritchie, IR Whittle. Department of Clinical Neurosciences, Western General Hospital, Edinburgh, UK

Diabetes mellitus is associated with vascular dysfunction and impaired cerebrovascular responsiveness. The role of diabetes in the evolution of ischaemia was considered in a rodent model of intracerebral haemorrhage.

Arterial blood or silicon oil $(50 \mu \mathrm{l})$ was injected into the striatum of both spontaneously diabetic insulin-treated rats and non-diabetic controls. After 24 hours, local cerebral blood flow (LCBF) was measured using $\left[{ }^{14} \mathrm{C}\right]$-iodoantipyrine autoradiography. LCBF was also measured in separate groups of non-lesioned animals treated acutely with saline, $N^{\mathrm{G}}$-nitro-L-arginine methyl ester (LNAME, $30 \mathrm{mg} / \mathrm{kg}$ intravenously), 7-nitroindazole (25 mg/kg intraperitoneally) or 3-morpholinosydnonimine (SIN-1, $1.8 \mathrm{mg}$ ) $\mathrm{kg} / \mathrm{h}$ intravenously)

In diabetic animals the volume of tissue surrounding the haematoma in which LCBF was between 15 and $35 \mathrm{ml} / 100 \mathrm{~g} / \mathrm{min}(2.04$ $(0.49) \mathrm{mm}^{3}$; mean (SEM)) was significantly larger than that found with oil injection $\left(0.21(0.08) \mathrm{mm}^{3}\right)$ and was also larger than in control animals injected with either blood $\left(0.27(0.15) \mathrm{mm}^{3}\right)$ or oil $\left(0.29(0.07) \mathrm{mm}^{3}\right)$. As reported previously, basal LCBF was sig nificantly reduced in the striatum of diabetic animals and their response to L-NAME was attenuated. By contrast, the response to 7 $\mathrm{NI}$ and SIN-1 was preserved in diabetic rats, indicating a specific perturbation of endothelial nitric oxide (NO) activity but preservation of neuronal NO in diabetes.
Diabetes mellitus influences the extent of ischaemia after haemorrhagic stroke. The blood itself and not the "mass" effect is responsible for the development of the penumbra. Impaired endothelial NO activity may be responsible for early exhaustion of vasodilatory capacity in diabetes after stroke and subsequent development of ischaemia.

BRAIN DERIVED NEUROTROPHIC FACTOR PREVENTS HYPOXIC/HYPOGLYCAEMIC DAMAGE IN ORGANOTYPIC HIPPOCAMPAL CULTURES

AK Pringle, LE Sundstrom, GJC Wilde, F Iannotti. Clinical Neurological Sciences, University of Southampton, Southampton General Hospital, Southampton, UK

Neurotrophins such as brain derived neurotrophic factor (BDNF) may form part of an endogenous neuroprotective mechanism after cerebral ischaemia. Although pretreatment with BDNF has been shown to prevent ischaemia neurodegeneration in vivo, this has not been replicated in vitro. We have investigated the effects of BDNF in a model of ischaemia more representative of the in vivo situation. Organotypic hippocampal slice cultures were prepared from 8-10 day old rat pups and maintained in vitro for 14 days. Ischaemia was simulated by exposure of cultures to $95 \% \mathrm{~N}_{2} / 5 \% \mathrm{CO}_{2}$ in glucose free medium for 60 minutes, after which cultures were returned to normoxic conditions for 24 hours. Cell death as determined by propidium iodide (PI) fluorescence and quantified using NIH Image 1.55 24 hours following 60 minutes ischaemia, significant PI fluorescence was present throughout CA1 (68.7 (4.9)\% of cell area). BDNF (0.1-100 $\mathrm{ng} / \mathrm{ml})$ produced a concentration dependent reduction in neuronal damage when present in medium for 24 hours before, during, and after the ischaemic episode. Damage was reduced to $10 \cdot 1$ (5.3)\% by $100 \mathrm{ng} / \mathrm{ml}$ BDNF. Further studies showed that $100 \mathrm{ng} / \mathrm{ml}$ BDNF was neuroprotective only if present during the 24 hours before ischaemia. These data suggest that preincubation with BDNF is necessary for neuroprotection, implying that transcriptional changes are required such as upregulation of other neuroprotective proteins.

A COMPARISON OF DIFFERENT METHODS OF EMBRYONIC DISSECTION USED TO OBTAIN STRIATAL TISSUE FOR INTRACEREBRAL TRANSPLANTATION IN THE RAT MODEL OF HUNTINGTON'S DISEASE

C Watts, A Rosser, SB Dunnett. MRC Centre for Brain Repair, Cambridge University, UK

Huntington's disease (HD) is an inherited progressive neurodegenerative condition characterised by movement, cognitive, and psychiatric disturbances, and involves the loss of intrinsic striatal neurons as its prominent pathological feature. The clinical features are not susceptible to pharmacological manipulation and neural transplantation being intensively investigated as a possible therapeutic alternative. In a rat model of $\mathrm{HD}$, foetal cells from the ganglionic eminence are transplanted into the lesioned striatum. The ganglionic eminence, which is divided into medial and lateral parts, gives rise to striatal primordium and adjacent structures such as globus pallidus, amygdala, and piriform cortex. Grafts derived from the lateral part may contain a greater proportion of striatal tissue than grafts derived from the medial part or the standard dissection of the whole eminence. A neuronal marker, microtubule associated protein (MAP-2) and a striatal specific marker, dopamine and adenosine 3:5 monophosphate-regulated protein (DARPP-32) in cell cultures have been used to compare the amount of striatal primordial tissue obtained from the different methods of embryonic dissection. Our results indicate that, used in conjunction, MAP-2 and DARPP-32 accurately identify striatal tissue obtained by different methods of embryonic dissection. This will facilitate further refinement of intrastriatal striatal grafts in the rat model of HD.

GENETIC DIFFERENCES BETWEEN FAMILIAL AND SPORADIC GLIOMAS

Dan Fults. University of Utah, Salt Lake City, Utah, USA

Tumours arising in cancer prone families result from inherited, germ line mutations in various genes controlling cell growth. In some hereditary cancer syndromes the defective gene has been identified, including the P53 gene in Li-Fraumeni syndrome, NF1 in von Recklinghausen's neurofibromatosis, APC in familial polyposis, and MTS1 in familial melanoma. Although the fundamental cause of CNS cancer is believed to be genetic, few brain tumour cases are inherited. An important question is whether brain tumours result from somatic mutations in the same genes that segregate in cancer families. To consider this question, DNA sequence analysis of four genes known to cause hereditary cancer syndromes (P53, NF1, APC, MTS1) was carried out in patients with sporadic gliomas. Various types of gene mutations in tumour cells were found but not in peripheral blood leucocytes from affected patients; mutation frequencies were much lower in these sporadic tutors than reported in familial cases. These results indicate that most gliomas in adults result from acquired, somatic mutations in cell growth control genes and not from inherited, germ line mutations.

FUNCTIONAL EXPRESSION OF A HUMAN TUMOUR SUPPRESSOR GENE (P53) IN RAT GLIOMA. AN EX VIVO MODEL

Victor CK Tse, Gerald D Silverberg. Molecular Neurosurgery Laboratory, Department of Neurosurgery, Stanford University School of Medicine, Stanford, USA

The functional expression of the human p53 gene leads to a reduction of tumour growth, both in vitro and in an ex vivo implantation. A retrovirus vector was used to insert p53 into a rat glioma cell line (RT-2). A significant retardation of the in vitro growth curve was seen and colony formation was significantly inhibited. Ex vivo implantation of the infected cells showed the integration of the transgene and its in situ expression resulting in a reduction of tumour volume. This study shows the effectiveness of tumour suppres- 
sor genes in the treatment of a brain tumour model. The mechanisms of growth suppression and the possible implications of adverse in vivo tumour selection were discussed.

GENE EXPRESSION IN EXPERIMENTAL ISCHAEMIA: PARALLELS WITH GENE EXPRESSION AFTER SURGERY FOR CONTUSIONS, INTRINSIC TUMOURS, AND EPILEPSY

PC Whitfield, VL Woodburn, JD Pickard. Academic Neurosurgical Unit and PDNRC, Addenbrooke's Hospital, Cambridge, UK

Adaptive cellular responses to external stimuli, such as cerebral ischaemia, involve the transcription and translation of DNA into proteins. These include inducible transcription factors (ITFs) which are fundamental to the stimulus-transcription response. ITFs may influence the outcome of each individual cell, and have been implicated in cell death mechanisms. The ITF response to forebrain ischaemia in the gerbil has been fully characterised. The pattern of ITF induction differed according to ischaemic duration and reperfusion time. Transitory induction of hippocampal c-fos and c-jun was observed. Induction of fun B was biphasic, with delayed expression evident in the selectively vulnerable CA1 subfield 24 and 72 hours after moderate ischaemia. NGFIA expression was induced in surviving dentate neurons. In addition, sustained glial activation in response to moderate ischaemia was seen throughout the hippocampus. Parallel studies on surgically resected tissue from patients with cerebral contusions $(n=13)$, intrinsic tumours $(n=$ $8)$, and intractable epilepsy $(n=3)$ were performed. c-fos was expressed in eight (33\%), and c-jun in $18(75 \%)$ patients. The induction of ITFs may be a direct response to the underlying pathology. Secondly, ITFs may be important in the pathogenesis of secondary events in disease. Specific blockade of ITF translation into proteins will help clarify the role of these factors in vivo.

FK-506 IMPROVEMENT IN RECOVERY AFTER SPINAL CORD INJURY: POSSIBLE ROLE OF GAP-43 EXPRESSION IN CALCINEURIN EFFECT

Joseph R Madsen, Paul MacDonald, Larry I Benowitz. Department of Neurosurgery, Children's Hospital, Boston, USA

Recent investigations have shown that FK506, in wide use as an immunosuppressant drug in transplantation, can stimulate neurite outgrowth in vitro, and can apparently diminish the size of experimental-cerebra infarcts in rats. The previously puzzling findings that the specific receptors for FK506 and similar drugs, called immunophilins, are more abundant in the CNS than in the immune system provide a theoretical mechanism for such activity. GAP-43, an intracellular phosphoprotein known to be involved in growth cone activity, is dephosphorylated by calcineurin, a target of the FK/immunophilin system. However, as there is a negligible quantity of GAP-43 in the uninjured spinal cord, significant upregulation of this protein in neurons would be necessary to implicate it in FK506 neuroprotection.

The effects of FK-506 given intra- venously to rats 10 minutes after photothrombotic thoracic spinal cord injury (1 $\mathrm{mg} / \mathrm{kg}$ ), and intraperitoneally at 24 and 48 hours after injury $(0.5 \mathrm{mg} / \mathrm{kg})$ were examined. Clinical benefit in the FK-506 group was evident at 21 and 28 days postinjury, both by Tarlov scores $(3 \cdot 1(0 \cdot 2) v 2 \cdot 3(0 \cdot 3)$ $P=0.024)$, and IP measurements $(51 \cdot 2$ (1.2) v 47.0 (1.3), $\mathrm{P}=0.046, \mathrm{df}=44)$

We now report that tissue obtained from similarly lesioned and treated animals showed scattered perilesional neurons strongly immunoreactive for GAP-43. Thus FK-506, an immunosuppressive agent which can promote neurite outgrowth in vitro, significantly improves the recovery after photothrombotic spinal cord injury. Mechanisms of this effect may involve modulation of the phosphorylation state of GAP-43 expressed in perilesional neurons.

CULTURE AND PRELIMINARY

CHARACTERISATION OF EPIDERMAL GROWTH FACTOR GENERATED MOUSE CNS STEM CELIS

T Ryken, C Watts, A Rosser, C Svendsen. Department of Neurosurgery, State University of New York Health Science Centre at Syracuse, Syracuse, New York, USA and MRC Centre for Brain Repair, University of Cambridge, Cambridge, UK

Cultures derived from embryonic mouse striatal primordia (E18) were initially propagated in serum free culture conditions using DMEM:F12 (1:1) supplemented with B27 media supplement and epidermal growth factor $(20 \mathrm{ng} / \mathrm{ml})$. After seven days the primary cultures were centrifuged, resuspended at a density of 20000 cells per $\mathrm{ml}$, and allowed to incubate an additional seven days. This resulted in colonies of free floating spheres of cells which could be propagated for up to eight weeks by seria subculture. These secondary cultures occasionally undergo spontaneous differentiation, adhere to the surface of the culture flask, and display a variety of cellular morphologies. These morphological alterations are enhanced by culturing the spheres ove poly-1-lysine coated glass coverslips and by removing the EGF from the culture media. Immunofluorescent studies using antibodies for GFAP, MAP, Gal C, nestin, beta-tubulin, NCAM, CD-56, and CDS7, result in a variety of staining patterns. These finding indicate that multiple phenotypes, both glial and neuronal, can result from prolonged culture of these primitive spheres. The continued characterisation of this culture system will not only enhance the study of developmental neurobiology but suggests a potentia renewable source of embryonic stem cells which may be of benefit in CNS transplantation.

INTRAOPERATIVE MRI: THE GENERAL ELECTRIC MRT SYSTEM

Eban Alexander III. Department of Surgery (Neurosurgery), Brigham and Women's and the Children's Hospitals, Harvard Medical School, Boston, USA

The prototype General Electric (GE) MR/T Intraoperative Magnetic Resonance Imaging System was designed to enable real time
MRI while performing major open operative procedures. The design of the imaging magnet was revised into two large tori, providing the best arrangement for optimisation of manual access for the surgeon and an assistant. Combined with specially designed surface coils, the system offers excellent image resolution.

High speed graphic computers are used to segment and register MR data sets, using a PIXSYS triple charged couple device (CCD) imaging system to correlate MRI spatial information with the system's spatial environment. The MR/T ( $T$ for "therapy") holds tremendous promise for complex neurosurgical resections, especially for infiltrative tumours or those with intimate attachments to critical neural and vascular structures, as well as for operative resection elsewhere in the body.

The ability of MR to analyse and quantify thermal gradients with high resolution enables the use of neodymium YAG laser, radiofrequency electrode, cryoprobe or focused ultrasound lesioning, and tumour ablation, carefully controlled through visualisation in $3 \mathrm{D}$ space.

The extent of tumour resection, lesioning electrode position, degree of spinal decompression, etc can be confirmed intraoperatively. The promise of such techniques as intraoperative functional brain imaging, image guided laser resection and focused ultrasound destruction of lesions emerge as promising future applications. Sophisticated virtual reality, supported by a robust intraoperative MR imaging device, offers the potential for a truly revolutionary surgical tool. Entire new vistas in neurosurgical intervention may open, mirroring the fundamental quantum leap that was enabled by the operating microscope a half century ago.

IMAGE DIRECTED PERCUTANEOUS SPINAL SURGERY

Patricia Littlechild, NV Todd. Newcastle General Hospital, Westgate Road, Newcastle upon Tyne, UK

There is currently no accurate method of using the technology of image guided surgery in minimally invasive spinal surgery. Previous attempts to develop a system have been hampered by the lack of a suitable method of registering the images to the patient. A new method is under development, in which a percutaneously placed guide wire provides the basis for registration. This method involves the use of a purpose built surgical robot, guided by orthogonal $x$ rays, to locate a surgical target within the spine. Preliminary trials are underway in phantoms, and show the system to be able to locate a target with a mean error of 2.5 $\mathrm{mm}$. Further modifications to the robot are expected to improve the accuracy. Proposed applications for this method include spinal biopsy, and placement of percutaneous lateral mass fixators in the cervical spine.

MORPHOMETRIC ANALYSIS OF THE AXIS, WITH PARTICULAR REFERENCE TO POSTERIOR SCREW FIXATIONS

G Solanki, AA Madawi, ATH Casey, HA Crockard. Department of Surgical Neurology, The National Hospital, Queen Square, London, UK 
While C 1-2 transarticular screw provides the most rigid fixation, there is a danger of vertebral artery injury. The question arises as to whether such injury is merely due to lack of technical experience or skills or because of specific anatomical variations.

The osteometric study consisted of 50 dry specimens of the second cervical vertebrae. Twenty one linear and five angular measurements were read using a PC linked electronic calliper with direct data download capabilities capable of $0.01 \mathrm{~mm}$ accuracy and a standard goniometer capable of $1^{\circ}$ accuracy.

A significant number of anatomical variations were observed. Internal vertebral groove erosions were noted in $22 \%$ of specimens and the height of the lateral mass thinned to $<2.1 \mathrm{~mm}$. Here clearly posterio screw insertions are an extreme risk to the vertebral artery, regardless of surgical skills.

In this study, the ideal drill angle for C1C2 transarticular screw, was anatomically between $0^{\circ}$ and $14 \cdot 19^{\circ}$, in the medial direction, aiming at the anterior tubercle of atlas; similar safe angles for the transpedicular screw were $32.39^{\circ}$ in the medial direction and $24.06^{\circ}$ in the superior direction from the point of insertion.

Due to great variations in the axis morphology and symmetry, failure to outline anatomical safe bounds preoperatively, may lead to unexpected surgical complications. Careful CT at the appropriate angle to visualise asymmetry and erosions should be done to exclude anatomical variations and help choose the right surgical approach for each case.

THE MYELOPATHY FUNCTIONAL DISABILITY INDEX: FUTURE DIRECTIONS

ATH Casey, HA Crockard, $M$ Bland. The National Hospital for Neurology and Neurosurgery, London, UK

The aim of the study was to measure disability caused by cervical myelopathy complicating rheumatoid arthritis.

The responses from 250 consecutive patients to the Stanford Health Assessment Questionnaire were prospectively recorded. Using principal components analysis on these results, the original questionnaire was reduced from 20 questions to 10 questions, to create a myelopathy functional disability index. In the second part of the study, the responses to this abbreviated questionnaire by those patients undergoing surgery from the original group of 250 patients were analysed with respect to outcome, to assess criterion related validity (predictive).

This method of data reduction resulted in no significant loss of information, reliability (internal consistency Cronbach's $=0.968$ ) or sensitivity. The new scale, the myelopathy disability index, measures only one dimension (Eigen value 6.97) and is more finely tuned to measuring disability in these myelopathic patients. When administered to the 194 patients undergoing cervical spine (group 2) surgery the myelopathy disability index was an accurate predictor of neurological and functional outcome, as well as survival after surgery $(P<0.0001)$. Responsiveness was also acceptable (standardised response mean, 0.4 and the effect size, 0.36 ).

The myelopathy disability index provides a user friendly, objective, and reliable means of assessing disability in patients with rheumatoid involvement of the cervical spine and also predicting outcome after surgical intervention. It also provides information for both the patient and surgeon alike, on what to realistically expect from surgery. Its adoption will facilitate comparisons between different forms of surgical intervention for cervical myelopathy. Other possible future uses will be discussed.

TREATMENT OF REFLEX SYMPATHETIC DYSTROPHY WITH SPINAL CORD STIMULATION

R Segal, S Baser, BR Stacey. Departments of Neurological Surgery, Neurology and Anesthesiology, University of Pittsburgh and Veterans Affairs Medical Centre, Pittsburgh, USA

Six patients diagnosed with reflex sympathetic dystrophy (RSD) who were refractory to conservative management underwent autonomic testing (quantitative sudomotor axon reflex test (Q-SART) and thermography) preimplantation and postimplantation of a spinal cord stimulator (SCS). The SCS induced reversal of the RSD syndrome with patients reporting satisfactory pain relief and being tapered off narcotics, as well as having resolution of swelling and discolouration of the involved limb. All the patients keep the stimulator turned on constantly; one patient required replacement of an exhausted battery in 12 months. The Q-SART following SCS demonstrated excessive resting output in 316 patients resolving in 215 patients studied for more than three months after implantation. Excessive, persistent sweat production (volume $7.64 \mu \mathrm{l}$ ) in $3 / 6$ patients resolved (volume $2 \cdot 17 \mu \mathrm{l}$ ), with normalisation of Q-SART curve morphology, and diminished active sweat production in $4 / 6$ patients improved in $2 / 5$ patients after implantation. The thermography studies demonstrated the temperature asymmetry, ranging from $2^{\circ}$ to $5^{\circ} \mathrm{C}$ decrease on the symptomatic limb in $6 / 6$ patients, clearly improved in all patients studied for more than three months, with less temperature asymmetry in two, no temperature asymmetry in one, and smaller area of temperature asymmetry in two.

HRP RETROGRADE LABELLING OF ANTERIOR HORN CELLS IN PERIPHERAL NERVE INJURY IN THE RAT

John Parker Mickle. Department of Neurosurgery, University of Florida, Gainesville, USA

Various models have been proposed in animals for the study of regeneration in peripheral nerves: three types of injury are most commonly employed: transection; pinch; and clipping. These three models were studied in three groups of rat sciatic nerve utilising the retrograde transport of horseradish peroxidase (HRP) to the anterior horn cell column as a measure of regeneration or injury. The retrograde transport and labelling of an anterior horn cell across an area of manipulation (suture, pinch, clip application) was defined as direct evidence of transport continuity from the periphery across the manipulated segment to the ante- rior horn cell. Six animals were in each group. Each animal had a four stitch repair of nerve transection, a 10 second pinch with jeweller's forceps, or a 30 second standard aneurysm clip application. Animals were then subjected to HRP application, $0.5 \mathrm{~cm}$ distal to the area of manipulation, on days 0 through 5. After HRP application, the animals were allowed to survive two days, after which they were perfused through the cardiac ventricle with saline and a mixture of paraformaldehyde and glutaraldehyde. The lumbosacral spinal cords were removed and sectioned horizontally at $50 \mu$ intervals. The contralateral sciatic nerve was labelled with HRP at the same time that the experimental side was labelled to have a control. Anterior horn cell labelling was then quantified by counting individual cells on the control and the experimental sides.

In the transection group of animals, anterior horn cell labelling did not appear on the experimental side until day five and represented only about $1 \%$ of control. HRP label was present in both the pinch and clip application groups on day 1 . This rapidly increased to about $40 \%$ of control by day 5 . These data suggest that the most common models used in defining injury and regeneration in peripheral nerve are very different systems when compared with a retrograde labelling technique used to define regeneration (pinch clip $v$ transection). The pinch and clip application groups would appear to represent not only regeneration, but also injury expression, with some fibres remaining intact after manipulation. These data suggest that a clearer definition of regeneration and peripheral nerve manipulation in experimental animals should be developed.

KLIPPEL-FEIL SYNDROME REVISITED:

DEVELOPMENTAL PATTERNS

Karoly M David, John M Stevens, $\mathrm{H}$ Alan Crockard. Department of Surgical Neurology, The National Hospital for Neurology and Neurosurgery, Queen Square, London, UK

The classic triad of Klippel-Feil syndrome is only present in about $50 \%$ of patients with congenital craniocervical junction anomalies which represent a wide variety in extent and clinical significance. To increase understanding of these abnormalities thorough retrospective analysis of plain $x$ ray films, CT, CT-myelograms and MRI of patients with congenital craniocervical junction fusion anomalies were performed. Special attention was given to fusion patterns and their possible embryological background.

In addition to the well known difference between fusion of ventral and dorsal parts of vertebrae there was almost invariably a pronounced difference between the fusion pattern on the left and right side. Atlantooccipital assimilation occurred with a wide range of subaxial vertebral and laminar fusions. Cervical split cord was always associated with extensive fusion of narrow and broad vertebral bodies with or without posterior spina bifida. The vertebral canal was usually very capacious similar to early embryological stages. Fusions involving the clivus, the odontoid, and long segments of the vertebral column are suspected to originate from anomalies of the notochord.

Illustrative cases with their embryological background were discussed. 
PATHOPHYSIOLOGY OF CHIARI MALFORMATION IN RELATION TO SYRINGOMYELIA: A STUDY OF CSF DYNAMICS WITH SPATIAL MODULATION OF MAGNETISATION

DE Sakas, CM Tolias, SC Wayte, DJ Beale, B Williams. Walsgrave Hospital and The Midlands Centre for Neurosurgery and Neurology, Birmingham, UK

Spatial modulation of magnetisation (SPAMM), an MRI technique used in assessing motion, was applied to the study of CSF flow in patients with syringomyelia and in healthy volunteers. Quantitative CSF flow velocity measurements were made in the anterior and posterior upper cervical subarachnoid space and inside the syrinx before and after craniocervical decompression. In patients the preoperative CSF velocities were found reduced at the upper cervical subarachnoid space by $26 \%$ ventral to and $73 \%$ dorsal to the spinal cord when compared with those of healthy volunteers. After craniocervical surgical decompression, SPAMM showed that CSF velocities increased by $94 \%$ and $42 \%$, ventral and dorsal to the cord respectively. Normalisation of CSF velocities in patients was highly predictive of clinical improvement. These results do not support previously proposed theories on the pathogenesis of syringomyelia, which rely on displacement of CSF from the ventricles into the central spinal canal. Conversely, they are in agreement with recent studies, which suggest that the injury to the cord and expansion of the syrinx are caused by displacement of CSF from the intracranial subarachnoid compartment to the spinal subarachnoid compartment.

NORMAL PRESSURE HYDROCEPHALUS SPECIFIC PATTERNS OF COGNITIVE CHANGE

Joanna L Iddon, John D Pickard, Barbara J Sahakian. Departments of Psychiatry and Neurosurgery, University of Cambridge, UK

In study I, 10 patients with normal pressure hydrocephalus (NPH) (shunted and nondemented) were assessed on standardised neuropsychological measures including verbal fluency, the mini mental state examination (MMSE), and on the computerised CANTAB battery.

Results showed a specific pattern of impairment on tests of "executive function" including attentional set shifting and planning.

In study II, 15 preshunt patients were subdivided into demented (group $1, \mathrm{n}=7$ ) and non-demented (group $2, n=8$ ) patients as identified by the MMSE. Test sessions took place preshunt and then again six months postshunt. The same test battery was given as in part I of the study, although group 1 patients were unable to complete most of these.

Group 1 showed a reversal of dementia postshunt but remained globally cognitively impaired. Group 2 showed a specific pattern of executive impairment both preshunt and postshunt, reflecting the same pattern of impairment as patients in study I. Subjective reports from patients and relatives in group 1 were of pronounced improvement in activities of daily living postoperatively.

In conclusion, sensitive neuropsychologi- cal tests can detect specific long term patterns of cognitive impairment in NPH.

ASSESSMENT SCALES AND THE COSTS OF SURGICAL PREVENTION OF STROKE

M Davis, A Radstock, M Deverill, RP Sengupta, AD Mendelow. Regional Neurosciences Centre, Newcastle General Hospital and Department of Health Economics, University of York, UK

Cerebrovascular disease is a major cause of death and disability and is responsible for a significant proportion of National Health Service expenditure. Carotid endarterectomy (CE) prevents ischaemic stroke in symptomatic patients with severe carotid arterial disease and surgical intervention also reduces the morbidity and mortality from aneurysmal subarachnoid haemorrhage (SAH). Analysis of the cost per quality adjusted life year has shown that such surgical intervention in SAH compares favourably with other surgical procedures. The risks and prognosis of surgical treatment may be related to clinical grading systems. In patients with carotid stenosis, the risk of carotid endarterectomy may be predicted by the Sundt risk classification, and in SAH, the World Federation of Neurosurgical Societies (WFNS) has proposed a five point grading system. This study has evaluated the costs of the surgical treatment of carotid stenosis and SAH in relation to these preoperative clinical grading systems.

The medical records of all patients who were admitted after SAH and who had subsequent surgical intervention (1990-2), or who underwent CE (1987-92), were examined. Patients were assigned to a preoperative risk category according to the WFNS or Sundt grading systems. The length of stay on the intensive care unit, high dependency unit, and in a neurosurgical ward was documented, along with the duration of time spent in neurosurgical theatres and the duration of surgery. All investigations and medications were recorded. Outpatient visits (CE patients) and resource implications arising from complications, including readmissions, repeat investigations, or repeat surgical intervention, were recorded. The duration of time spent with patients by medical personnel and other healthcare professionals was documented. Costs were divided into direct, indirect, and overhead and cost information was obtained for each ward type, from the neurosurgical theatre suite, and from the outpatient department. The mean cost per episode of care was calculated

Hospital costs of stroke prevention

\begin{tabular}{|c|c|}
\hline \multicolumn{2}{|c|}{ Carotid endarterectomy } \\
\hline Sundt grade & Cost in $£$ (mean) \\
\hline $\begin{array}{l}\text { I } \\
\text { III } \\
\text { IV }\end{array}$ & $\begin{array}{l}2625 \\
2828 \\
4117 \\
3243\end{array}$ \\
\hline \multicolumn{2}{|c|}{ Subarachnoid haemorrhage } \\
\hline WFNS grade & Cost in $£$ (mean) \\
\hline $\begin{array}{l}\text { I } \\
\text { I } \\
\text { III } \\
\text { IV } \\
\text { V }\end{array}$ & $\begin{array}{r}4272 \\
5232 \\
7187 \\
6825 \\
11546\end{array}$ \\
\hline
\end{tabular}

and related to preoperative grade.

Poorer preoperative grades were associated with higher mean costs.

Preoperative grading may predict the subsequent costs of surgery for stroke preven tion and may be important in cost benefit analysis.

RELIABILITY OF NEAR INFRARED

SPECTROSCOPY (NIRS) IN THE ASSESSMENT OF $\mathrm{CO}_{2}$ REACTIVITY IN PATIENTS WITH CEREBROVASCULAR DISEASE

P Smielewski, PJ Kirkpatrick, M Czosnyka, JD Pickard. Academic Neurosurgical Unit, Addenbrooke's Hospital, Cambridge, UK

The reliability of near infrared spectroscopy (NIRS) and reproducibility of the $\mathrm{CO}_{2}$ reactivity test results have been studied in patients with cerebrovascular disease. Twenty patients with symptomatic carotid stenosis were examined. Signals end tidal $\mathrm{CO}_{2}$, arterial blood pressure (Finapress), flow velocity (FV) in the middle cerebral artery (transcranial Doppler (TCD)), $\mathrm{SaO}_{2}$ (pulse oximeter), $\mathrm{Hb}$, and $\mathrm{HbO}_{2}$ (NIRS) and extracranial microcirculation (laser Doppler flux (LDF)) have been digitised and recorded continuously. The protocol consisted of two sets of $5 \% \quad \mathrm{CO}_{2}$ challenges - one on each side-with a break of five minutes between them. At the end of each recording two brief compressions of the superficial temporal artery were performed. Ten patients were re-examined within the next two days using the same protocol.

Both TCD (FV) and NIRS showed some variation in reactivity to $\mathrm{CO}_{2}(23 \% \mathrm{FV}, 22 \%$ $\mathrm{HbO}_{2}, 31 \% \mathrm{Hb}, 35 \% \mathrm{Hbt}$ ) between the two consecutive challenges. Higher differences in both FV and NIRS reactivities were usually associated with variation in ABP. Superficial temporal artery compression confirmed that with a $6 \mathrm{~cm}$ interoptode distance $\mathrm{HbO}_{2}$ is some four times more sensitive to changes in $\mathrm{CBF}$ than extracranial circulation.

The reliable assessment of $\mathrm{CO}_{2}$ reactivity using either TCD or NIRS should include repeated $\mathrm{CO}_{2}$ challenge and careful analysis of the influence of change in ABP.

A PROSPECTIVE AUDIT OF ANEURYSMAL SUBARACHNOID HAEMORRHAGE COMPARING EARLY AND LATE SURGERY

PJA Hutchinson, H Seeley, PC Whitfield, PJ Kirkpatrick. Academic Neurosurgical Unit, Addenbrooke's Hospital, Hills Road, Cambridge, UK

The results are reported for an ongoing prospective audit of outcome of patients with aneurysmal subarachnoid haemorrhage (SAH). The effect of timing of surgery on (a) three month Glasgow outcome score (GOS) and (b) length of neurosurgical stay was sought.

A standard proforma has been used since September 1992 for recording the demographic and clinical details of all patients with SAH admitted to the East Anglian Regional Neurosurgical Unit. Data were independently collected by the Clinical Audit Department.

Between September 1992 and December 1995, 420 patients were admitted with SAH (mean age 53.1 years; range 16-89 years; $59 \%$ female). The mean time from bleed to hospital admission was 2.4 days. 259 
patients underwent clipping of aneurysm at mean time $6 \cdot 1$ days postbleed.

Fifty nine per cent of the operated patients underwent early ( $0-4$ days) surgery (mean 2.3 days) and $41 \%$ late ( $>4$ days) surgery (mean 10.0 days). Both groups were well matched for demographic features and severity of SAH. The outcome at three months was favourable (GOS1 and GOS2) in $84 \%$ of the early group and $85 \%$ of the late group. The operative mortality rate at three months was $7 \%$ and $9 \%$ respectively. The length of stay was significantly shorter (95\% CI $\mathrm{P}<0.001$ ) for those undergoing early surgery (mean time 16.6 days) compared with those undergoing late surgery (23.2 days). In this unit this corresponds to a saving of 759 inpatient hospital days per year.

Surgical outcome is independent of the timing of aneurysm surgery, but those who undergo late surgery have a longer inpatient stay.

TIMING OF ANEURYSMAL SURGERY IN ELDERLY PATIENTS

H Fernandes, A Jenkins, NV Todd, RP Sengupta, PJ Crawford, AD Mendelow. Newcastle General Hospital, Newcastleupon-Tyne, UK

There is a trend towards early clipping of aneurysms after subarachnoid haemorrhage (SAH), especially in the good grade patient. Reluctance to extend this to elderly patients, however, still exists, with the expectation that they will do worse.

Data were collected prospectively on all patients admitted to the Neurosurgical Department at Newcastle General, with SAH, from 1991-5.

Surgical clipping of an aneurysm was carried out in 416 patients. Early surgery (three days or less from ictus) was carried out in 209 patients under 65 years. One hundred and seventy eight $(85 \cdot 2 \%)$ made a favourable recovery (Glasgow outcome score: good recovery or moderately disabled at six months). One hundred and thirty six had delayed surgery (4 to 79 days, mean 10), $119(87.5 \%)$ of whom made a favourable recovery.

Over the same period 27 patients, 65 years of age or older, had aneurysmal clipping within three days, 20 made a favourable recovery. Of the 44 that had delayed surgery (4 to 90 days, mean 12 days), 32 made a favourable recovery. A $\chi^{2}$ test showed no significant difference between these observed frequencies $(P=$ 0.54 and 0.9 ). All four groups were comparable in terms of admission and preoperative WFNS grade ( $t$ test admission grade, $P=$ 0.75 , preoperative grade, $P=0.9$ ).

These data would suggest that whereas the rate of favourable recovery is not statistically higher in the under 65 age group, the more elderly population do not fare worse if operated for aneurysmal rupture within three days.

ENDOTHELINS IN CEREBRAL VASOSPASM: EFFECT OF ORAL ANTAGONIST RO47-0203 IN PATIENTS

D Grosset, GM Teasdale, W Taylor, AD Mendelow, A Wallnoeffer, R Jones. Institute of Neurosurgical Sciences, Glasgow, Neurosurgery, Newcastle, UK and Roche Pharmaceuticals, Basle, Switzerland
Experimentally, endothelins cause severe cerebral vasoconstriction and high concentrations are found in the CSF of patients with vasospasm after subarachnoid haemorrhage. In a multicentre study we have investigated the effect of Ro47-0203 (Bosentan), a competitive selective antagonist of endothelin I at A and B receptors in patients with Doppler evidence of vasospasm within 14 days of subarachnoid haemorrhage.

Twenty four patients were studied, each had undergone operation for a ruptured aneurysm and had been shown by serial studies with transcranial Doppler sonography (TCD) to have a recent pronounced increase in middle cerebral artery flow velocities (MCAFV). Patients were randomised to receive placebo $(n=6)$ or Ro47-0203 (n =18) $500 \mathrm{mg}$ intravenously over $30 \mathrm{~min}$ utes. TCD measurements were made two hours before infusion, continuously four hours afterwards, and serially for 24 hours and blinded interpretation made according to predetermined criteria. Of 18 actively treated patients only one patient showed a continuing increase in MCAFV; in seven patients MCAFV remained stable. Six patients showed a probable and four a definite decrease in velocity. In the five patients in the placebo group three showed a further increase in velocity, one showed stable values; probable or definite decreases in velocity were seen in only two.

These preliminary results encourage further studies of the role of endothelins in cerebral vasospasm and exploration of the potential of endothelin antagonists for clinical treatment.

INTRAOPERATIVE HYPOTHERMIC PROTECTION DURING ANEURYSM SURGERY: A PILOT CLINICAL TRIAL

CM Loftus, MM Todd, JC Torner, A Gelb, R Craen, A Schubert, $M$ Mahla. The University of Iowa College of Medicine, 200 Hawkins Drive, Iowa City, USA

A multicentre randomised, prospective trial of intraoperative hypothermia in aneurysm patients is presented. Candidates included patients in WFNS grades I-III, with preSAH Rankin scores of 0,1 , or 2 . Preoperative and postoperative neurological assessment employed the NIH stroke scale (blinded examiner), with examinations performed immediately before surgery, and at 1,3 , and 7 days, and 6 and 12 weeks after surgery. Outcome at three months was based on the Glasgow outcome scale.

The surgical team was blinded as to group assignment. All patients underwent standardised isoflurane $/ \mathrm{N}_{2} \mathrm{O} /$ fentanyl anaesthetic. Oesophageal temperature was controlled using forced air warming/cooling, water mattress, and heated humidification. Hypothermic arm patients were cooled to a target of $\approx 33.5^{\circ} \mathrm{C}$ at clip application, then rewarmed as quickly as possible. Normothermic arm patients were maintained at $36 \cdot 5^{\circ} \mathrm{C}$.

The trial began in January 1995; 70 patients had been entered at five centres by December 1995. Initial data survey indicates that target temperatures were reached in $75 \%$ of hypothermic patients, with a group mean temperature of $33.8^{\circ} \mathrm{C}$. There were no obvious untoward effects of cooling. Additional preliminary data were presented. The pilot trial will be halted after 100 patients have been entered and recruitment of added international centres will be sought to permit the design/completion of a larger, definitive trial (estimated size $\approx 1500$ patients).

INTERNAL AND EXTERNAL CAROTID CONTRIBUTION TO NEAR INFRARED SPECTROSCOPY (NIRS) DURING CAROTID ENDARECTOMY (CE)

JMK Lam, PJ Kirkpatrick, P Al-Rawi, P Smielewski, JD Pickard. Academic Neurosurgical Unit, University of Cambridge, Cambridge, $\mathrm{UK}$

Sixteen patients undergoing CE were studied. Transcranial Doppler monitoring middle cerebral artery flow velocity, laser-Doppler flux (LDF) monitoring scalp blood flow, cerebral function monitor, and NIRS (Hamamatsu) were placed on the side of operation. Data were recorded continuously.

The external carotid artery (ECA) was clamped for two minutes followed by internal carotid (ICA) clamping. After CE, the ECA and the common carotid artery clamps were released. It was followed by release of ICA in two minutes.

Interrupted time series analysis was used to compare parameters before and after clamping or release of an artery. Reduction in $\mathrm{HBO}_{2}$ and increase in $\mathrm{HB}$ as measured by NIRS were detected after clamping of ICA in 10 cases, ECA in 10 cases, and both in seven cases. The changes were inconsistent in three cases because of fluctuation in blood pressure. In six of the seven cases, where both ICA and ECA contributed to NIRS, ICA contributed more. Hence, NIRS depended predominantly on ICA in $9 / 16$ cases and on ECA in $4 / 16$ cases. ECA dependence had a strong association with ipsilateral severe ICA stenosis and no severe stenosis at the other ICA and ECAs. Changes in NIRS after clamping or release of ECA had a strong association with significant corresponding changes in LDF, but there was no such association after clamping or release of ICA.

TRANSCUTANEOUS DETECTION OF CHANGES IN OXYHAEMOGLOBIN CONCENTRATION IN RESPONSE TO INTERNAL CAROTID INJECTIONS OF RADIOCONTRAST MEDIA USING NEAR INFRARED SPECTROSCOPY

TJ Germon, PD Evans, N Barnett, P Wall, TT Lewis, RJ Nelson. Department of Neurosurgery, Frenchay Hospital, Bristol, UK

Near infrared spectroscopy (NIRS) may be used to monitor transcutaneously concentrations of oxy and deoxyhaemoglobin in a tissue volume, the size of which is thought to be proportional to the separation between the NIR light emitter and detector. Internal carotid (IC) arteriography results in a transient displacement of oxygenated haemoglobin from the arterial and capillary bed. Time-resolved, multichannel NIRS was used to detect reduction in oxyhaemoglobin concentrations in the frontal region after $10 \mathrm{IC}$ injections (10 patients five men, three women: mean age 42.5 years) undergoing elective IC arteriography before epilepsy surgery. We predicted greater reductions in oxyhaemoglobin concentration at increasing emitter-detector separations due to the increasing proportion of cerebral tissue remit- 
ting NIR light to the mcre distal detectors.

A significant reduction was found in oxyhaemoglobin concentration in the $0-10 \mathrm{sec}$ onds after injection of the radiocontrast medium at all emitter-detector separation from $0 \cdot 7-5 \cdot 5 \mathrm{~cm}$. However, when adjusted for mean photon path length the magnitude of the reduction was not dependent on emitter-detector separation.

These results differ from a similar study using intra-arterial indocyanine green dye which has been used to validate dual-channel NIRS. They suggest that a significant amount of radiocontrast passes into the extracerebra tissues during IC arteriography or that, due to optical channelling, most photons detected pass through extracerebral tissues.

NON-INVASIVE NEAR INFRARED SPECTROSCOPY MEASUREMENTS OF HBO CORRELATED WITH INVASIVE DYNAMIC MICROPOLARGRAPHIC $\mathrm{PO}_{2}$ VALUES IN NON-TRAUMATIC HYDROCEPHALIC PATIENTS AT DRAINAGE

GS Cruikshank, R Duckworth. Departments of Neurosurgery and Neuro-Anaesthesia, Institute of Neurological Sciences, Southern General Hospital, Glasgow, UK

The ability of non-invasive NIRS to reflect parenchymal brain tissue oxygenation is in question. The effect of scalp and skull attenuation may limit the NIRS signal derived from brain tissue. This study sets out to correlate the relation between direct tissue $\mathrm{PO}_{2}$ measurements and noninvasive NIRS data from patients with nontraumatic hydrocephalus recorded at the time of pressure correction by ventricular puncture. The major assumption in this model is that hydrocephalus exerts a uniform effect of pressure on the parenchymal substrate for NIRS and $\mathrm{PO}_{2}$ recordings.

Ten patients with hydrocephalus due to congenital aqueduct stenosis (two), posterior fossa tumours (three), or shunt malfunctions (five) were entered into this study. The Critikon 2001 NIRS system was used to noninvasively evaluate the change in brain $\mathrm{HbO}_{2}$ in the left frontal region. Invasive brain access was via a right frontal burr hole which allowed a dynamic micropolarographic and ventricular puncture pressure measurements to be made during a continuous recording of NIRS. With conditions otherwise unaltered the effect of ventricular puncture and decompression was monitored.

Intraventricular pressure varied at puncture from 44 down to $10 \mathrm{~mm} \mathrm{Hg}$, and was brought down to a drainage height of $10 \mathrm{~cm}$ of water. There was an immediate improvement in monitored median tissue $\mathrm{PO}_{2}$ which was more pronounced at higher pressure levels. There was a good direct correlation between the median $\mathrm{PO}_{2}$ and change in $\mathrm{HbO}_{2}$. There was a close inverse correlation between these factors and ventricular pressure.

In all cases the effect of a decrease in pressure by ventricular puncture was to improve the $\mathrm{HbO}_{2}$ and median tissue $\mathrm{PO}_{2}$ measurements. The response to dropping pressure seems to be due to a direct pressure effect on microcirculation as the improvement in oxygenation appears rapid. This study provides evidence that the correlation between $\mathrm{HbO}_{2}$ measured non-invasively and median tissue $\mathrm{PO}_{2}$ measured invasively is good in such a circumscribed model.
ASSESSMENT OF CEREBRAL HAEMODYNAMICS USING SPATIALLY RESOLVED SPECTROSCOPY

PG Al-Rawi, P Smielewski, H Hobbiger, G Dhond, S Ghosh, PJ Kirkpatrick. University Department of Neurosurgery, Cambridge University, Cambridge, UK

Spatially resolved spectroscopy (SRS, Hamamatsu Photonics) is a new development for deriving a quantitative measure of cerebral oxygen saturation non-invasively. SRS delivers near infrared light (four wavelengths) via a common scalp optode. Back scattered light is detected at three closely placed scalp receivers which theoretically samples light that has followed a similar path An algorithm is used to calculate absolute concentrations of haemoglobin $(\mathrm{Hb})$ and oxyhaemoglobin $\left(\mathrm{HbO}_{2}\right)$, and hence mean cerebral haemoglobin saturation.

This machine has been incorporated into a multimodality monitoring system for the purpose of validating SRS\% saturation agains jugular bulb oxygen saturation $\left(\mathrm{SjO}_{2}\right)$, in patients undergoing routine cardiopulmonary bypass $(\mathrm{CPB})$ procedures $(\mathrm{n}=24)$. Data were digitised and recorded real time.

Correlation between $\mathrm{SRS}$ and $\mathrm{SjO}_{2}$ measurements varied from patient to patient $(r=$ $0 \cdot 08-0 \cdot 97)$. Overall the range of changes seen with the SRS were not as great as those seen with $\mathrm{SjO}_{2}$ measurements. SRS tended to give readings that were $10-15 \%$ lower than $\mathrm{SjO}_{2}$ readings.

SRS provides a new means of assessment of cerebral oxygenation; however, the results of this study suggest that SRS is not, as yet, a reliable monitor of cerebral oxygen saturation during CPB. Variables affecting transmission of light into and through cerebral tissue are complex. Calibration of this technique is difficult, and requires further investigation and adjustment, possibly using different clinical scenarios.

LUMBAR CEREBROSPINAL FLUID PRESSURE MONITORING USING THE NEW CODMAN MICROSENSOR

H Fernandes, E Bashir, A Jenkins. Newcastle General Hospital, Newcastle-upon-Tyne, UK

Direct measurement of CSF is required on many patients with hydrocephalus. The most accurate method, with an intraventricular catheter, is invasive. Some lumbar methods exist, but the new Codman intracranial pressure (ICP) monitoring system has yet to be validated in this role.

The Codman MicroSensor ICP transducer consists of a strain gauge pressure sensor mounted at the tip of a flexible nylon catheter.

Three patients, with differing pathological causes of communicating hydrocephalus wer monitored using this device. Raised pressure was demonstrated in two patients, and their symptoms settled with operative CSF diversion. One patient with normal pressures and headaches settled with Pizotifen.

The Codman catheter removes the need for a CSF column and its inherent problems, and because it is flexible lends itself to intrathecal placement. It can be secured without risk of fracture, unlike fibreoptic devices. It has been validated as an accurate device in the laboratory, and there is some preliminary data to confirm ventricular accuracy. We have successfully used it in three patients for the measurement of lumbar CSF pressure, with maximum patient comfort, and no breakages. Although comparative readings are not available, the satisfactory clinical results bear witness to its reliability.

STATISTICAL ISSUES IN COMPARISONS OF INTRACRANIAL PRESSURE MONITORING DEVICES

DF Signorini. Department of Clinical Neurosciences, Western General Hospital, Edinburgh, UK

The comparison of two methods of measuring the same physical parameter when neither can be considered a "gold standard" is a recurring problem in medical research Typical analysis of the problem involves plotting one measurement against the other and calculating the correlation coefficient. It has been argued that it is more informative to plot the difference between measurements against their average.

The nature of intracranial pressure (ICP) monitoring devices implies that comparison studies generally involve few patients, each of whom contributes many measurements. This implies that not all of the paired measurements are statistically independent, and that Bland-Altman plots may not be adequate.

This paper aims to show that a more rigorous analysis which takes this non-independence into account can illustrate features of the physical processes which are not readily apparent using "standard" methodology. The motivating and illustrative example is an in vivo comparison of an intraparenchymal Codman ICP monitoring device with both intraparenchymal and intraventricular Camino devices, which is ultimately analysed using a mixed effects ANOVA model.

CORRELATION BETWEEN SLOW WAVES IN INTRACRANIAL AND ARTERIAL PRESSURE: A NEW INDEX OF CEREBROVASCULAR REACTIVITY

M Czosnyka, P Kirkpatrick, P Smielewski, D Menon, JD Pickard. Academic Neurosurgical Unit, Addenbrookes Hospital, Cambridge, UK

Association between changes in arterial pressure (AP) and intracranial pressure (ICP) depends on the cerebrovascular reactivity reserve. An index was developed for the continuous monitoring of this association and verified in a group of 82 severely head injured patients. AP, ICP, and transcranial Doppler blood flow velocity in MCA (FV) was recorded daily (20 minutes to two hour periods). The slow waves response index (SWRx) was calculated as a moving correlation coefficient between 30 consecutive samples of averaged (over six seconds) values of ICP and AP. Positive SWRx correlated significantly with greater ICP $(r=0.496 ; P<0.00001)$, lower CPP $(r=0.36 ; \mathrm{P}<0.001)$, and poor outcome (at six months after injury: $r=0.46$; $P<0.00001)$. Correlation of the SWRx with transcranial Doppler index of autoregulation (correlation between time average FV and CPP) was very close: $r=0.63 ; \mathrm{P}<0.000001$. SWRx was positive $(P<0.05)$ during the first two days after injury, but only in patients with an unfavourable outcome.

Computer analysis of slow waves in AP and ICP is able to provide continuous index of absent (positive SWRx) or intact (zero or negative SWRx) vascular reactivity. Absent reactivity is predictive of poor outcome. 